one attempt within a year. Please include all relevant cases, irrespective of whether or not they were admitted to hospital. Do not include "successful" attempts with fatal outcome.

It is sometimes difficult to distinguish between a suicidal threat or gesture and a suicidal attempt. The latter should be defined as any act of self-damage undertaken with the apparent intention of self-destruction, however half-hearted and ineffective. The patient may have been only vaguely aware of this intention, which sometimes has to be inferred from his actions. The degree of actual danger to life, as seen from our point of view, is not relevant for inclusion in this group ; many attempts which to us seem harmless are undertaken with serious intent, and vice versa. The questionary has a category for doubtful cases.
We should be glad to answer any questions you might wish to ask us.

Thanking you for your co-operation, Yours sincerely,

REFERENCES

Farberow, N. L., and Shneidman, E. S. (1961). The Cry for Help. McGraw-Hill, New York.

James, I. P., Derham, S. P., and Scott-Orr, D. N. (1963). Med. F. Aust., 1, 375.

Kessel, N., and Lee, E. M. (1962). Scot, med. 7., 7, 130.

Rüegsegger, P. (1963). Psychiat. et Neurol. (Basel), 146, 81

Rüegsegger, P. (1963). Psychiat.
Stengel, E. (1963). Lancet, 1, 233.

and Cook, N. G. (1958). Attempted Suicide. Chapman and Hall, London.

\title{
A Controlled Therapeutic Trial of Various Diets in Ulcerative Colitis
}

\author{
RALPH WRIGHT,* M.D., D.PHIL., M.R.C.P. ; S. C. TRUELOVE,* M.D., F.R.C.P.
}

Brit. med. F., 1965, 2, 138-141

Andresen (1925) was the first to suggest that ulcerative colitis might be due to food allergy. He continued to study the disease in this light and later reported that in two-thirds of his patients one or more specific items of the diet appeared to be the principal aetiological factor in the disease, with cow's milk as the most important, while others were wheat, tomatoes, oranges, potatoes, and eggs (Andresen, 1942). Closely similar conclusions were reached by Rowe (1942).

Since then there have been occasional reports of apparent allergy to milk or other foods in patients with ulcerative colitis (Sarles et al., 1959 ; Rider et al., 1960). However, the difficulty in assessing the value of eliminating a particular food from the diet in a disease in which remissions and relapses are variable and unpredictable has made this contention difficult to prove.

Our own interest in this possibility arose when a small group of patients with ulcerative colitis who had become symptom-free on a milk-free diet all relapsed when milk was reintroduced into the diet (Truelove, 1961). By taking into account the average relapse rate in ulcerative colitis it was estimated that the odds were more than 1,000 to 1 against this run of relapses after challenge being due to chance. Although this finding strongly suggests that milk may be a factor in the aetiology of ulcerative colitis so far as some patients are concerned, it does not provide proof.

It seemed essential to test the therapeutic value of a milk-free diet in ulcerative colitis under more stringent conditions than in previous studies. We have therefore made a controlled clinical trial of various diets in this disease. In view of the findings of Taylor and Truelove (1961) that patients with ulcerative colitis are more likely than normal subjects to have high titres of circulating antibodies to two of the purified proteins of cow's milk, the immunological reactions to several dietary proteins have been studied in parallel.

The results of the clinical study are now presented. The immunological findings are only mentioned briefly, as they are being reported in detail separately (Wright and Truelove, 1965).

\section{Experimental Design}

Patients presenting with an attack of ulcerative colitis were allocated at random to one of three dietary groups: (a) a milk-

* Nuffield Department of Clinical Medicine, the Radcliffe Infirmary, Ox́ord. free diet ; (b) a gluten-free plus milk-free diet ; and (c) a control group on a "dummy" diet.

A stratified design was used to ensure a close balance between the three dietary groups. The patients were divided into those seen during the first attack and those seen during a relapse of established disease. The patients in relapse were further divided into those patients with a short history, of less than three years; those with a medium history, of three to 10 years; and those with a long history, of 10 years or more. Patients in each of these clinical categories were allotted at random to the dietary groups, employing restricted randomization to keep the numbers in the three dietary groups approximately equal.

\section{Selection of Patients}

All patients, whether in-patients or out-patients, seen during an attack of ulcerative colitis confirmed by sigmoidoscopy and barium enema examination, were admitted to the trial, provided that: (a) they were prepared to keep to a strict diet for a period of one year and to attend for follow-up at monthly intervals ; (b) they had not already been on treatment with corticosteroids for the attack for more than one week; and (c) no major complication of ulcerative colitis was present.

\section{Non-dietary Treatment}

In addition to the diet all patients were given a standard course of medical treatment with prednisolone by mouth in a dose of $5 \mathrm{mg}$. six-hourly for six weeks and hydrocortisone hemisuccinate $100 \mathrm{mg}$. nightly by rectal infusion for two months, together with any general medical measures necessary for the particular case. If the attack was severe enough to warrant admission to hospital the dose of prednisolone was doubled and the rectal infusion used twice daily. All patients were given two tablets of Omnivite Forte for the period of the trial. A similar course of treatment was given for each relapse (as defined below) during the trial period.

\section{Dietary Treatment}

At the time of admission to the trial the patient was told the nature of the diet in general terms and was then referred to a dietitian, who explained it in more detail. A diet sheet was 
prepared for each of the diets and a cyclostyled copy was given to the patient.

The milk-free, low-roughage diet excluded all milk and milk products whether in the form of dairy produce such as fresh milk and cheese or as powdered milk. Butter was permitted. This is the same diet as that on which some patients with ulcerative colitis had remained symptom-free and subsequently relapsed when milk was reintroduced into the diet (Truelove, 1961). The gluten-free plus milk-free diet was a modification of the gluten-free diet used in this hospital in the treatment of idiopathic steatorrhoea, but all milk and milk products were excluded in addition. Butter was not permitted and the patients were told to use margarine instead.

Patients on the "dummy" diet were instructed to exclude a variety of items of diet, such as fried foods, condiments, and ice cream, but constituents of these foods which might be antigenic were included in the list of other foods which were permitted. In particular, they were advised to consume milk and milk products liberally.

At each subsequent visit the patients were asked whether they had been keeping to the diet, and any problems which arose were discussed-if necessary, with a dietitian.

At the end of one year the patients were asked to go back to a normal diet. Those who had been on a diet which excluded both milk and gluten were allowed gluten products initially and milk was reintroduced one month later.

\section{Data Recorded During the Trial}

On admission to the trial the patient was asked the frequency and nature of the stools in the previous 24 hours and whether or not they contained blood. The information was recorded, using a simple code.

A sigmoidoscopy was performed and the mucosal appearance classified as normal, mild inflammation, or marked inflammation. A rectal biopsy was taken at 3 to 5 in. $(7.5$ to $12.5 \mathrm{~cm}$.) from the anal margin, using a Truelove-Salt suction biopsy instrument.

A sample of blood was taken for the following investigations: (a) haemoglobin and erythrocyte sedimentation rate (E.S.R.); (b) total eosinophil count; and (c) serum for immunological studies. Patients were seen fortnightly for the first month and thereafter once a month during the trial period of one year. At each visit the clinical state and sigmoidoscopic findings were recorded on a special record card and a rectal biopsy and a blood specimen obtained.

Relapses During Trial.-A relapse was defined as diarrhoea with an average of four or more stools a day for at least a week and with macroscopic blood present, together with sigmoidoscopic evidence of diffuse inflammation. When these criteria were fulfilled the patient was treated along standard lines with prednisolone by mouth for six weeks and rectal hydrocortisone for eight weeks as before.

Withdrawal from Trial.-Patients were withdrawn from the trial if: (a) the attack continued to be severe and required either surgical treatment or treatment with systemic corticosteroids for more than six weeks; or (b) three successive relapses, in addition to the initial attack, had occurred during the trial period.

\section{Results}

In all, 77 patients were admitted to the trial.

During the course of the trial it became clear that many patients on the gluten-free plus milk-free diet found that this was an unattractive diet and were unable to maintain strict adherence to it. In addition it was found that milk protein had inadvertently been included, since some brands of margarine and some articles included in the gluten-free diet contained quite large quantities of powdered milk. This group was therefore excluded for purposes of comparison.

The clinical course of patients on the milk-free and dummy diets, as judged by the number of relapses of ulcerative colitis developing during the trial period, is compared in Table I. This shows that patients on a milk-free diet had fewer relapses than those on the dummy diet. Ten patients on a milk-free diet remained well for the year compared with five on a dummy diet. Three patients had three relapses and were withdrawn from the trial in the milk-free group compared with eight in the control group. One patient on a dummy diet failed to respond to high-dosage corticosteroids within the stipulated period and had to be withdrawn from the trial.

TABLE I.-Results of Clinical Trial of Diet in Ulcerative Colitis (Milk-

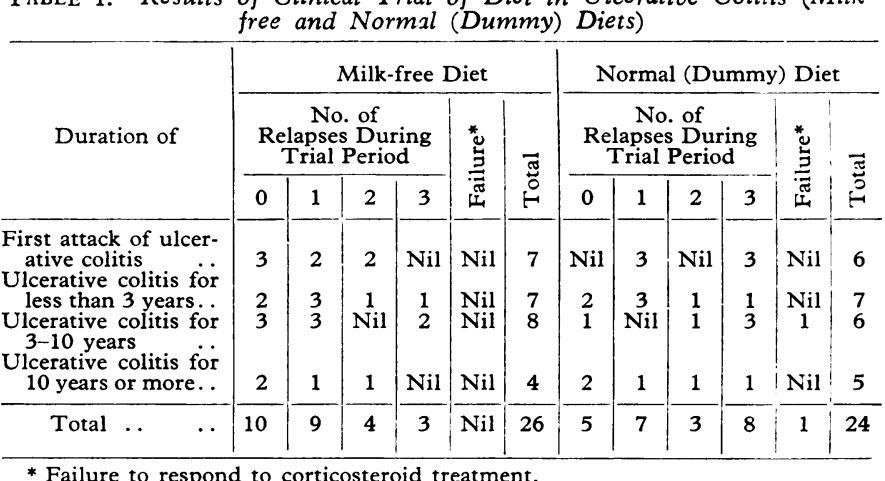

Since the cases were randomized in subgroups according to the length of history of the colitis the groups can be compared among patients seen in the first attack, with a short, witn a medium, or with a long history of colitis. It can be seen from Table I that, although patients on a milk-free diet fared better than those on the dummy diet irrespective of the length of history, the maximum benefit occurred in patients seen during the first attack.

Details of the statistical method used for comparing the two groups are given in the accompanying Appendix by Mr. G. J. Draper. This shows a significant difference in favour of the milk-free group as compared with the control group.

A comparison of the results obtained with the milk-free diet and the normal (dummy) diet are given in the Chart. From this it can be seen that it is the two blocks at the ends of the scale which are different with the two diets. If about $20 \%$ of the patients on the dummy diet were transferred from the worst group to the best, the results for the two diets would be similar. In other words the results suggest that about one in every five patients with ulcerative colitis will do badly on an ordinary diet but well on a milk-free diet.

Table II shows that patients on what we had intended to be the most restricted diet (the gluten-free plus milk-free diet)

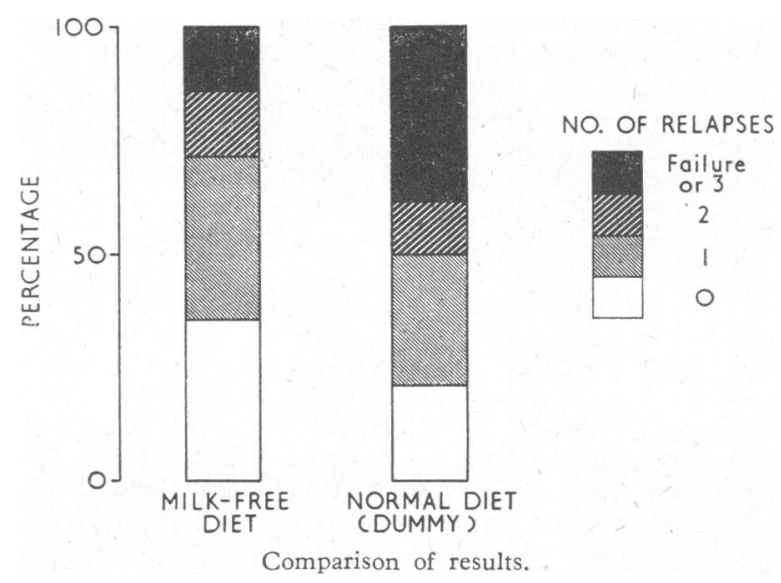


relapsed almost as often as the control group. If a milk-free diet is beneficial, a diet also excluding gluten could be expected to be at least as good. For reasons mentioned above it was clear that some patients in this group in fact failed to exclude milk or gluten or both from the diet. They might therefore be regarded as an additional "control" group, but the results do not enable any firm conclusions to be drawn about the role of a gluten-free diet in ulcerative colitis.

\begin{tabular}{|c|c|c|c|c|c|c|}
\hline & \multicolumn{4}{|c|}{$\begin{array}{l}\text { No. of } \\
\text { Relapses During } \\
\text { Trial Period }\end{array}$} & \multirow{2}{*}{$\begin{array}{l}\text { Failure to } \\
\text { Respond to } \\
\text { Corticosteroid } \\
\text { Treatment }\end{array}$} & \multirow[t]{2}{*}{ Total } \\
\hline & 0 & 1 & 2 & 3 & & \\
\hline $\begin{array}{l}\text { First attack of ulcerative colitis } \\
\text { Ulcerative colitis for less than } 3 \text { years } \\
\text { Ulcerative colitis for } 3-10 \text { years } \\
\text { Ulcerative colitis for } 10 \text { years or more }\end{array}$ & $\begin{array}{l}2 \\
2 \\
3 \\
1\end{array}$ & $\begin{array}{l}3 \\
1 \\
2 \\
1\end{array}$ & $\begin{array}{c}1 \\
2 \\
\mathrm{Nil} \\
1\end{array}$ & $\begin{array}{l}2 \\
2 \\
2 \\
1\end{array}$ & $\begin{array}{l}\text { Nil } \\
\text { Nil } \\
\text { Nil } \\
1\end{array}$ & $\begin{array}{l}8 \\
7 \\
7 \\
5\end{array}$ \\
\hline Total & 8 & 7 & 4 & 7 & 1 & 27 \\
\hline
\end{tabular}

\section{Additional Clinical Observations}

Certain additional clinical observations support the conclusion that a milk-free diet is beneficial in a proportion of patients with ulcerative colitis. These observations are of several different types:

\section{Previous Response to a Milk-free Diet}

Among the patients included in the trial there were two who had previously responded well to a milk-free diet and relapsed when milk was reintroduced. It is interesting to compare their clinical course in the present trial.

A married woman aged 35 was Case 3 of the earlier clinical study (Truelove, 1961). For three and a half years she was symptomfree on a milk-free diet and relapsed six weeks after milk was reintroduced. Thereafter she was well on a milk-free diet from the beginning of 1960 until 1962. In February of that year the passage of blood per rectum occurred, and sigmoidoscopy showed active inflammation. She was admitted to the present trial and fell into the dummy-diet group. She relapsed three times in rapid succession and was withdrawn from the trial after eight months. She was then returned to a milk-free diet, and since then has been entirely well, with a normal sigmoidoscopy picture, during the 21 months that have elapsed. Comment : This patient was previously sceptical of the value of a milk-free diet, and it is possible that the minor relapse which brought about her admission to the present trial was due to her failing to adhere to it strictly.

A married woman aged 37 was Case 4 of the earlier study (Truelove, 1961). She was put on a milk-free diet with benefit in 1955 after a period of three years of repeated attacks of ulcerative colitis. From 1955 onwards she remained well on the milk-free diet, but twice relapsed when milk was deliberately reintroduced. In June 1962 she developed diarrhoea with blood and was found to be actively inflamed on sigmoidoscopy. She was admitted to the present trial and fell into the milk-free group. The relapse responded swiftly to treatment and she remained well and sigmoidoscopically normal throughout the one year's trial period and also during the 12 months which have since elapsed. She has refused any further challenge with milk. Comment: The contrast between this patient and the previous one is striking.

\section{Corticosteroid Dosage}

As already mentioned, some patients were treated with double the standard dosage of corticosteroids because the attack was failing to respond. The number of patients needing to be treated in this way provided an additional criterion for judging the relative merits of the diets employed. Only three of the patients on the milk-free diet required such treatment, whereas seven of those on the dummy diet did so, one of them on two occasions.

\section{Challenge by Milk}

Six of the ten patients who were symptom-free on a milk-free diet throughout the trial period were subsequently challenged by the reintroduction of cow's milk into the diet. Three of them had rapid relapses but responded well to a short course of corticosteroids plus a milk-free diet, and have since remained well on a milk-free diet. A fourth developed abdominal pain, diarrhoea, and mild sigmoidoscopic abnormalities, but she promptly stopped taking milk and settled without corticosteroid therapy.

\section{Discussion}

The present study has shown that a milk-free diet is beneficial to a certain proportion of patients with ulcerative colitis. Our best estimate from the figures is that about one in every five can be expected to do well on a milk-free diet whereas he would repeatedly relapse on a standard diet. There is a suggestion that the proportion may be higher in patients in their first attack of the disease, but our numbers are small and further observations will be necessary to clarify this point.

The way in which a milk-free diet acts when it is beneficial is obscure. 'The first, and most obvious, possibility is that in some patients ulcerative colitis is an allergic disease and cow's milk proteins can be the responsible allergens. If so, additional evidence might come from immunological reactions, which in turn could conceivably be used to pick out those patients who would respond favourably. Our own immunological observations have proved fruitless in this particular respect, but it is possible that circulating antibodies are inappropriate to the present problem, and we judge that other types of immunological reaction deserve to be studied.

A second possibility is that ulcerative colitis is not an allergic disease in its very nature but that secondary allergic reactions can be set up and can then dominate the clinical course. Against this possibility is our finding that a milk-free diet appears to be more effective in first attacks than in chronic disease, although this is a point which requires further numbers for certainty.

A third possibility is that cow's milk is harmful to some patients not through its proteins being allergenic but because it contains other substances which may be harmful. For example, a variety of substances can be secreted in milk, depending upon the particular diet of the cow. Recently the use of penicillin in veterinary medicine has been responsible for hypersensitivity reactions because of the trace of penicillin present in the milk of treated cows (Vickers et al., 1958).

A further possibility is that milk has no direct connexion with ulcerative colitis but acts in some indirect manner. For example, the bacterial flora of the large bowel may be dependent on the type of diet, and it is conceivable that bacteria are of some consequence in ulcerative colitis, although there is virtually no evidence that the disease is caused by a bacterial infection in the ordinary sense of this term.

\section{Summary}

A controlled therapeutic trial of various diets has been carried out in 77 patients with ulcerative colitis. Patients with a frank attack of uncomplicated ulcerative colitis were allotted at random within a stratified design to one of three diets: (a) milkfree, $(b)$ gluten-free plus milk-free, and $(c)$ dummy. The attack was treated with corticosteroids in a standard manner and the patients were regularly observed over a trial period of one year. 
A relapse was defined as the occurrence of diarrhoea with blood in the stools for at least one week, accompanied by sigmoidoscopic evidence of inflammation.

The milk-free diet was superior to the dummy diet. There were twice as many of the patients on the milk-free diet who were symptom-free throughout the trial period of a year as there were on the ordinary diet, while, conversely, fewer patients suffered from several relapses.

From our figures, the best estimate appears to be that a milkfree diet is beneficial to about one in five patients with ulcerative colitis, with a suggestion that the proportion may be higher in patients in their first attack of the disease. The titres of circulating antibodies to the principal proteins of cow's milk provide no guide to the clinical response.

The results obtained with the gluten-free plus milk-free diet were closely similar to those obtained with an ordinary diet, but these results were vitiated because it transpired that some patients were unable to adhere strictly to this diet and that certain items of the diet contained milk proteins, although these had been included in the diet in ignorance of this fact.

The possible modes of action of a milk-free diet are briefly discussed.

We are indebted to Miss R. E. Longstaff and the other dietitians of the Radcliffe Infirmary for their assistance.

\section{REFERENCES}

Andresen, A. F. R. (1925), Med 7. Rec. (Suppl.), 122, 271

And (1942). Amer. F. dig. Dis., 9, 91

Rider, J. A., Moeller, H. C., Devereaux, R. G., and Wright, R. R. (1960). Rider, J. A., Moeller, H. C., Devereaux, R. G.,
Acta allerg. $(K b h),$.15 , Suppl., 7, p. 486.

Acta allerg. (Kbh.), 15, Suppl., 7, p. 486.
Rowe, A. H. (1942). Ann. intern. Med., 17, 83.

Sarles, H., Deck, M., Chalvet, H., and Ambrosi, L. (1959). Arch. Mal. Appar. dig., 48,'907.

Taylor, K. B., and Truelove, S. C. (1961). Brit. med. F., 2, 924.

Truelove, S. C. (1961). Ibid., 1, 154.

Vickers, H. R., Bagratuni, L., and Alexander, S. (1958). Lancet, 1, 351.

Wright, R., and Truelove, S. C. (1965). Brit. med. f., 2, 142.

\section{Appendix}

\section{Remarks on the Statistical Analysis}

\section{G. J. DRAPER, * M.A.}

In the present situation, as often happens with medical data, the ordinary $x^{2}$ statistic is not appropriate for analysing the results shown in Table $I$. The usual form of analysis is designed merely to detect whether differences exist between rows -that is, whether the proportions in each column vary significantly from one row to the next. Equally, of course, one may say that the $\chi^{2}$ test is designed to see whether the proportions in each row vary from one column to the next or, again, whether the row and column classifications are independent.

* Unit of Biometry, Oxford University.
However, this form of analysis does not take into account the fact that one or both of the row and column classifications may be quantitative or at any rate ordered-that is, that there may be progression in the classifications such as Better/Same/ Worse. In cases such as these a statistical test is required that is designed not simply to detect differences between the rows of the table but to be sensitive to differences which show a trend in some particular direction-that is, which is specially designed for the situation where one is interested in testing whether the observations in one row show a general shift towards the "good" end of the scale as compared with the other row.

A test which will be appropriate when two treatments are being compared and the outcomes are ordered categories has been given by Cochran (1954), Armitage (1955), and Bradford Hill (1961). In order to apply the test some form of scoring has to be applied to the ordered categories-that is, each column or row has to be allotted a numerical value.

This test was applied in the present case, using as the score the number of relapses.

\section{Results}

The results are concerned with a comparison between the milk-free diet and the dummy diet.

In analysing the results a decision has to be made whether the single patient who failed to respond to treatment at all should be included or not. If he is included the modified $\lambda^{2}$ value-that is, using the test described above-is $4.52(\mathrm{P}<0.04)$. In computing this $\chi^{2}$ the patient on the "dummy" who failed to respond was given the worse possible score-that is, was assumed to have had the maximum number of relapses (three). Since scores on this diet tend in any case to be worse (higher) this procedure maximizes the apparent difference between diets. If this patient is excluded altogether the difference appears less, $x^{2}=3.57(0.05<P<0.06)$.

On the usual criterion the first $\lambda^{2}$ value would be judged significant and the second would be non-significant. But these inferences are based on a two-tailed test. By this is meant that in testing significance one considers that treatment differences in either direction are possible. However, if one is prepared to make the assertion that only one treatment could be superior -that is, in the present case, that the milk-free diet certainly cannot be worse than the ordinary ("dummy") diet-then the appropriate test for making inferences is a one-tailed test and in this case the significance probabilities given above would be halved. If one is prepared to accept that such procedure is in fact appropriate then the results are significant at the conventional $5 \%$ level-even with the exclusion of the case referred to.

\section{REFERENCES}

Armitage, P. (1955). Biometrics, 11, 375.

Cochran, W. G. (1954). Ibid., 10, 417.

Hill, A. Bradford (1961). Principles of Medical Statistics, 7th ed. The Lancet, London. 